\title{
O LIQÜIDO CEFALORRAQUEANO INICIAL NA MENINGITE TUBERCULOSA
}

Jỗo Bapt:sta dos ReIS

O exame do líqüido cefalorraqueano na meningite tuberculosa é de suma importância, vindo auxiliar de modo absoluto o diagnóstico da moléstia. Por êste motivo, diversos autores, há muito tempo, têm-se preocupado com o estudo de suas alterações nessa entidade mórbida. De modo geral, são concordes em admitir um conjunto de modificações mais ou menos constantes.

Assim. tomando por base os estudos de Merritt e Fremont-Smith em 84 casos de meningite tuberculosa (comprovados pela presença de bacilos ao exame direto ou na inoculação em cobaia do líqüido cefalorraquidiano, ou pela autópsia), as seguintes alterações foram encontradas, em média: a pressão geralmente estava aumentada, ao redor de $37 \mathrm{~cm}$ de água; o aspecto foi límpido ou opalescente, porém em nenhum dos casos purulento; a côr variou do incolor ao xantocrômico; houve formação de retículo fibrinoso em todos os casos. O número de células se achava aumentado, encontrando-se pleocitose de 25 a 500 por $\mathrm{mm}^{3}$, de tipo linfomononuclear predominante. A taxa de proteínas variou de 0,25 a $11,40 \mathrm{~g} / \mathrm{l}$, apresentando-se en média ao redor de $2 \mathrm{~g} / \mathrm{l}$. A taxa de glicose oscilou entre 0,05 e $0,59 \mathrm{~g} / \mathrm{l}$, tendo como valor médio $0,28 \mathrm{~g} / \mathrm{l}$. As taxas de cloretos apresentaram-se entre 4,71 e $7,53 \mathrm{~g} / \mathrm{l}$, em média $6,08 \mathrm{~g} / \mathrm{l}$. A reação de Wassermann foi sempre negativa, a não ser em 2 casos nos quais houve superposição de meningite tuberculosa e neurolues. Frisam os autores que, nos indivíduos luéticos, devido a uma permeabilidade maior da barreira hemoliquórica, pode haver passagem de reaginas sifilíticas, surgindo então uma reação de Wassermann positiva. Afirmam ainda que nenhuma dessas alterações constitui isoladamente sinal patognomônico de meningite tuberculosa, porém, no conjunto, formam uma síndrome liquórica raramente encontrada em outras moléstias. A presença do bacilo de Koch no exame direto e, principalmente, pela inoculação em cobaia, são os únicos dados de certeza diagnóstica.

Se a pleocitose na grande maioria das vêzes é de tipo linfomononuclear, pode, raramente, ser de tipo predominantemente polinuclear. Outros autores acham que a pleocitose é mais intensa no adulto que na criança.

E' fato bastante conhecido a dificuldade técnica da demonstração do bacilo ao exame direto pelos métodos comuns utilizados em laboratório 
clínico. Alguns autores julgam ser possível essa demonstração no esfregaço do sedimento do líquor na grande maioria dos casos, desde que cuidados especiais sejam dispensados. Essa afirmação não tem sido confirmada pela maioria dos autores, os quais têm verificado apenas $40 \%$, em média, de resultados positivos da baciloscopia direta.

0 maior interêsse atual pelo diagnóstico precoce da meningite tuberculosa, dada a possibilidade da sua cura, o que outrora não existia, nos levou a fazer um estudo sôbre as alterações do líqüido cefalorraquidiano inicial nessa moléstia, como etapa prévia a outros trabalhos que pretendemos elaborar.

\section{MATERIAL}

Reunimos no presente estudo 143 casos de meningite tuberculosa, divididos em dois grupos. $O$ primeiro consta de 92 casos, dos quais em 68 o exame bacterioscópico direto foi positivo e em 24 após inoculação en cobaia. $U$ segundo reune os 51 casos restantes, nos quais a pesquisa do bacilo foi negativa, não tendo sido feita a inoculação por motivos diversos. Havia, entretanto, alterações do líquor sugestivas de meningite tuberculosa (pleocitose média, do tipo linfomononuclear predominante; aumento da taxa de proteínas totais; presença de retículo fibrinoso; diminuição da taxa de glicose) e quadro clínico de meningite crônica, tendo sido demonstrado foco tuberculoso no paciente ou em pessoa de sua convivência diária, elementos êstes que permitiram o diagnóstico.

A punção foi feita, na grande maioria dos casos, de 7 a 30 dias depois de instalada a moléstia.

Dêsses 143 pacientes, puderam ser conhecidas as idades em 138, is quais se distribuíram de acôrdo com o seguinte quadro de frequiência (m. = meses; a. = anos) :

\begin{tabular}{r|c|c|c|c|c|c|c|c|}
\hline $3 \mathrm{~m} .-1$ & a. & $1-10$ a. & $11-20$ a. & $21-30$ a. & $31-40$ a. & $41-50$ a. & $51-60$ a. & $61-70$ a. \\
\hline 12 & 69 & 24 & 20 & 9 & 3 & - & 1 \\
\hline
\end{tabular}

Como se pode observar, em mais da metade dos casos a moléstia se apresentou antes dos 10 anos.

\section{RESULTADOS}

O exame do líqüido cefalorraquidiano inicial dêsses casos mostrou os dados seguintes:

Pressão - A pressão inicial só pôde ser verificada em boas condições técnicas em 54 casos. Estes pacientes se achavam calmos e cooperantes, ou comatosos e constatamos os seguintes valores para a pressão inicial, medida com o manòmetro de Claude:

\begin{tabular}{c|c|c|c|c|c|c|c}
\hline Crn de água & $11-20$ & $21-30$ & $31-40$ & $41-50$ & $51-60$ & $61-70$ & $71-80$ \\
\cline { 2 - 4 } N.0 de casos & 6 & 12 & 16 & 10 & 5 & 3 & 2 \\
\hline
\end{tabular}


Este quadro mostra que não observamos caso algum de hipotensão; a pressão foi normal em 6 . Na grande maioria, portanto, foi verificada uma hipertensão discreta, média ou grande. Dêstes casos pudemos medir a pressão final em 48, de maneira a permitir calcular o índice de Ayala $(Q R)$, que nos ofereceu os seguintes dados:

\begin{tabular}{|c|c|c|c|c|c|c|}
\hline $\mathrm{QR}$ & 2 a 3 & 3,1 a 4 & 4.1 a 5 & 5,1 a 6 & 6,1 a 7 & 7,1 a 9 \\
\hline N.o de casos & 11 & 11 & 15 & 6 & 4 & 1 \\
\hline
\end{tabular}

Estes números vêm demonstrar fatos aparentemente discordantes; como se tratam de índices de Ayala $(\mathrm{QR})$ em casos de meningite, era de se esperar cifra normal ou alta; entretanto, verificamos que, em 37 vêzes o índice estava abaixo de 5 e, apenas em 11 vêzes, acima dêsse número. Tal. vez êsse fato tenha sua explicação no aumento do volume encefálico, visto como a meningite tuberculosa não é um processo puro das meninges, mas sim uma meningoencefalite.

Aspecto - $\mathrm{O}$ aspecto do líquor foi límpido em 42 casos e opalescente em 101.

Côr - Em 26 casos foi verificada discreta xantocromia, e nos demais o líquor se apresentou incolor.

Retículo fibrinoso - Com exceção de 2 casos, em todos os demais houve formação do retículo fibrinoso. Atribuímos êsses dois casos à deficiência do método de observação.

Exame citológico - A contagem global das células, feita nos 143 casos, apresentou-se da seguinte maneira:

\begin{tabular}{c|c|c|c|c|c|c|c}
\hline Células $/ \mathrm{mm}^{3}$ & $0-5$ & $5,1-20$ & $21-50$ & $51-100$ & $101-200$ & $201-500$ & $501-2000$ \\
\hline N.o de casos & 1 & 2 & 18 & 24 & 40 & 47 & 11 \\
\hline
\end{tabular}

A média foi de 242 células por $\mathrm{mm}^{3}$. Fizemos também estudo comparativo entre a pleocitose e a idade do paciente, verificando não haver relação entıe ambas.

A contagem específica foi feita pelo método hematológico em 40 casos. nos quais se basearam estas nossas considerações, excluindo aquêles em. que foi utilizado o método de coloração supra vital.

Houve predominância absoluta de linfócitos na grande maioria dos casos. Sòmente em 5 vêzes os linfócitos se mostraram em percentagem in. ferior a $50 \%$. A menor percentagem verificada foi de $22 \%$, sendo a média de $77 \%$. Sua freqüência de distribuição foi a seguinte: 


\begin{tabular}{c|c|c|c|c}
\hline$\%$ & 0.50 & $51-70$ & 71.80 & $81-100$ \\
\hline N. ${ }^{\circ}$ de casos & 5 & 3 & 8 & 24 \\
\hline
\end{tabular}

Os mononucleares foram encontrados na quase totalidade dos casos em percentagem pequena. A maior percentagem verificada foi de $14 \%$, sendo a média de $4 \%$. A freqüência de distribuição foi a seguinte:

\begin{tabular}{c|c|c|c|c}
\hline$\%$ & 0 & 1.5 & $6-10$ & 11.20 \\
\hline N.o de casos & 1 & 25 & 13 & 1 \\
\hline
\end{tabular}

Os plcismócitos foram encontrados em mais da metade dos casos. em. bora em pequena percentagem na média de $2 \%$, com a seguinte distribuição:

\begin{tabular}{c|c|c|c|c|c}
\hline$\%$ & 0 & $1-2$ & $2,1-4$ & $4,1-8$ & $8,1-10$ \\
\hline N.0 de casos & 17 & 16 & 3 & 3 & 1 \\
\hline
\end{tabular}

Foram encontrados granulócitos neutrófilos em 33 casos. A maior percentagem encontrada foi de $76 \%$, sendo a média de $16 \%$. A distribuição obedeceu à seguinte freqüência:

\begin{tabular}{c|c|c|c|c|c}
\hline$\%$ & $1-5$ & $5,1-10$ & $11-20$ & $21-50$ & $51-80$ \\
\hline N.0 de casos & 9 & 5 & 9 & 7 & 3 \\
\hline
\end{tabular}

Os granulócitos eosinófilos ocorreram muito raramente apenas em 5 dos 40 casos estudados e assim mesmo na percentagem de $1 \%$; a média foi de $0,1 \%$.

Os granulócitos basófilos foram ainda mais raros, sendo verificados em apenas 3 casos. $\mathrm{Em}$ duas vêzes a percentagem foi de $1 \%$ e em uma vez de $0,5 \%$. A média foi de $0,05 \%$.

Proteinas totais — A determinação da taxa de proteínas totais foi feita nos 143 casos, revelando os seguintes resultados: 


\begin{tabular}{c|c|c|c|c|c}
\hline g/litro & $0,10-0,25$ & $0,26-1$ & $1,01-2$ & $2,01-3$ & $3,01-8$ \\
\hline N.o de casos & 3 & 78 & 46 & 9 & 7 \\
\hline
\end{tabular}

Em apenas 3 casos a taxa de proteínas totais foi normal. A maior taxa encontrada foi de $7,60 \mathrm{~g} / \mathrm{l}$. 0 valor médio foi $1,16 \mathrm{~g} / \mathrm{l}$.

Reações das globulinas - As reações de Pandy, Weichbrodt e Nonne ofereceram os seguintes resultados:

\begin{tabular}{|c|c|c|c|c|c|c|}
\hline \multirow{2}{*}{ Reação } & \multirow{2}{*}{ N.O de casos } & \multicolumn{5}{|c|}{ Intensidade } \\
\hline & & Neg. & + & ++ & +++ & $++t+$ \\
\hline Pandy $\ldots \ldots \ldots$ & 143 & 2 & 26 & 44 & 61 & 10 \\
\hline Weichbrodt $\ldots$ & 115 & 54 & 35 & 14 & 12 & 0 \\
\hline Nonne $\ldots \ldots \ldots$ & 1.42 & 7 & 56 & 59 & 19 & 1 \\
\hline
\end{tabular}

O estudo comparativo destas reações revelou uma grande sensibilidade da reação de Pandy, que apresentou resultados aproximadamente semelhantes aos das proteínas totais, com apenas duas reações negativas, correspondentes aos casos nos quais a taxa de proteínas foi normal. A reação de Nonne acompanhou, embora com menor sensibilidade, a reação de Pandy. A reação de Weichbrodt, entretanto, revelou grande número de resultados negativos, mostrando ser a menos sensível, fato êsse em franco contraste com o que se observa nos casos de neurolues.

Reação do benjoim coloidal -- Esta reação foi feita em 138 casos, cujos resultados mostraram que, em nenhum dêles, a curva foi normal; havia alargamento da faixa média em 30 casos; floculação da $1^{\text {a }}$ e $2^{\text {z }}$ zonas em 29; floculação da $2^{\text {a }}$ e $3^{\text {* }}$ zonas em 64; curva atípica em 15 casos. Estes resultados demonstram o predomínio da floculação nos tubos da $2^{\text {a }}$ e $3^{\text {a }}$ zonas, curva coloidal esta também chamada de "meningítica". Sòmente em 29 casos foi observada a floculação da $1^{\text {a }}$ e $2^{\text {a }}$ zonas, também conhecida como curva de "tipo paralítico".

Reação de Takata-Ara - Foi feita em 132 casos, tendo sido encontrados os seguintes resultados: negativa em 19 casos; positiva tipo vermelho em 89; positiva tipo floculante em 21 ; positiva tipo misto em 3 . Verificamos por esta reação um grande número de resultados negativos; porém, como na reação do benjoim coloidal, houve predomínio franco do tipo vermelho sôbre o floculante. 
Taxa de cloretos - Determinada em 142 casos, com os seguintes resultados:

\begin{tabular}{c|c|c|c|c|c|c}
\hline g/litro & $5-5,50$ & $5,51-6$ & $6,01-6,50$ & $6,51-7$ & $7,01-7,60$ & $7,61-8$ \\
\hline N.o de casos & 1 & 7 & 40 & 64 & 28 & 2 \\
\hline
\end{tabular}

Sòmente em 19\% dos casos a taxa de cloretos foi normal. A grande maioria revelou números abaixo de $7 \mathrm{~g} / \mathrm{l}$. Em apenas 2 casos verificamos aumento da taxa. A menor taxa constatada foi de $5,38 \mathrm{~g} / \mathrm{l}$. O valor médio foi $6,67 \mathrm{~g} / \mathrm{l}$.

Taxa de glicose - A determinação da taxa de glicose foi feita nos 143 casos e os resultados obtidos foram os seguintes:

\begin{tabular}{c|c|c|c|c|c|c|c}
\hline g/litro & $0,01-0,10$ & $0,11-0,20$ & $0,21-0,30$ & $0,31 \cdot 0,4 J$ & $0,41-0,50$ & $0,51-0,80$ & $0,81-1$ \\
\hline N.o de casos & 9 & 20 & 35 & 40 & 20 & 16 & 3 \\
\hline
\end{tabular}

Em apenas 19 casos foi obtida taxa normal ou acima do normal (13\%). A menor taxa verificada foi de $0,05 \mathrm{~g} / \mathrm{l}$ c a maior foi de $0,98 \mathrm{~g} / \mathrm{l}$. Em média, a taxa de glicose foi de $0,34 \mathrm{~g} / \mathrm{l}$.

Reação de Wassermann - Foi feita em 137 casos, tendo sido sempre negativa, com exceção de uma vez, na qual foi observado um resultado positivo. Tratava-se de uma criança luética portadora de tuberculoma encefálico, que foi operado posteriormente e na qual se manifestou meningite tuberculosa.

Reação de floculação de Eagle - Foi feita em 126 casos, sendo: negativos 121, duvidosos 3 e positivos 2 .

Reação de Steinfeld - Foi feita em 89 casos e todos os resultados foram negativos.

Reação de fixação do complemento para cisticercos - A prova foi feita em 86 pacientes, tendo sido obtidos 84 resultados negativos e 2 positivos inspecíficos. Nestes 2 casos não havia granulócitos eosinófilos.

Exame bacterioscópico direto - A pesquisa de bacilos álcool-ácido resistentes foi positiva em 68 casos e negativa nos demais. Se aos nossos 143 casos somarmos 43 outros que muito provàvelmente também eram de meningite tuberculosa e que nós excluímos dêste trabalho por não ter sido 
possível determinação do foco contagiante, teremos então 68 baciloscopias diretas positivas sôbre um total de 186 , ou seja $36,5 \%$.

Inoculação em cobaia - Em 30 casos em que foi feita, 6 dêles já com exame direto positivo. Os resultados foram todos positivos.

Baseados nos resultados obtidos nos exames de 143 casos de meningite tuberculosa, verificamos que a fórmula média do líquor é a seguinte: pressão inicial, $37 \mathrm{~cm}$ (manômetro de Claude), paciente em decúbito lateral; aspecto opalescente; côr incolor; retículo fibrinoso presente; células por $\mathrm{mm}^{3} 242$ (morfologia celular: linfócitos $77,85 \%$. mononucleares $4 \%$, plasmócitos $2 \%$, neutrófilos $16 \%$, eosinófilos $0,1 \%$, basófilos $0,05 \%$ ); prcténas totais $1,16 \mathrm{~g} / \mathrm{l}$; reações das globulinas Pandy +++ , Weichbrodt + , Nonne ++; reação do benjoim coloidal 00000.22222.22200.0; reação de Takata-Ara positiva (tipo vermelho); cloretos $6,67 \mathrm{~g} / \mathrm{l}$; glicose $0,34 \mathrm{~g} / \mathrm{l}$; reação de Wassermann negativa; bacilo de Koch (exame direto, inoculação) presente.

\section{COMENTARIOS}

A constância das alterações do líquor nos casos de meningite tuberculosa e sua persistência durante todo o longo curso da moléstia, constituem elementos importantes no diagnóstico dessa afeeção. $E^{\prime}$ verdade que, na fase inicial, de instalação do processo, pode-se observar um tipo de alteração inespecífica do líquor, um simples quadro de irritação meníngea, porém, o exame de uma segunda amostra, colhida aproximadamente uma semana após, vem revelar as modificações características da síndrome na meningite tuberculosa. A êste propósito relatamos a observação de um caso em que êste fato ficou bem evidenciado. Trata-se da paciente T. D., para a qual fizemos dois exames iniciais, o primeiro em 1-6-1948 e o segundo em 7-6-1948, tendo-se obtido os seguintes resultados:

\begin{tabular}{c|c|c|c|c|c|c|c|c|c|c}
\hline P. inicial & Retic. & Cél. & Linf. & Prot. & P. & W. & N. & Cl. & Glic. & B.K. \\
\hline \hline \multirow{2}{26}{} & - & 237 & $84 \%$ & 0,32 & + & - & - & 7,37 & 0,61 & - \\
58 & + & 293 & $76 \%$ & 0,79 & +++ & + & +++ & 6,90 & 0,34 & + \\
\hline
\end{tabular}

Infelizmente, o achado do bacilo álcool-ácido resistente no exame direto é bastante raro ( 30 a $40 \%$ das vêzes para a maioria dos autores). Por isso ficariam sem diagnóstico etiológico imediato mais da metade dos casos. Daqui se deduz a importância dêste conjunto de alterações do líquor, que por si só pode permitir o diagnóstico de meningite tuberculosa. 
Assim, mesmo na ausência do bacilo álcool-ácido resistente, só pelo exame do líquor, quando esta síndrome se apresentar em tôda sua expressão (líquor hipertenso, com delicado retículo fibrinoso, pleocitose média de tipo linfomononuclear predominante, aumento das proteínas totais, diminuição da taxa de glicose) e, ainda, quando estas alterações tiverem um caráter persistente tomando-se por referência exames de amostras de líquor com intervalos de uma semana, a suspeita de meningite tuberculosa assume uma posição primacial no raciocínio clínico, justificando uma atitude terapêutica, enquanto a prova da inoculação em cobaia segue seu curso lento para afinal dar o resultado objetivo da etiologia do processo. As vantagens do início precoce do tratamento específico são inegáveis.

Este ponto de vista tem sua razão de ser, porque sòmente em raras circunstâncias êste tipo de alteração do líquor pode-se prestar a confusões. Analisando tais circunstâncias, verificamos que: a) na meningite luética, na qual às vêzes a taxa de gllicose pode estar diminuída, as reações de Wassermann e a de floculação para sífilis são positivas, fazendo-se assim o diagnóstico diferencial; b) na cisticercose encefálica, em raras ocasióes, podemos observar alterações do líquor que se possam assemelhar àquelas da meningite tuberculosa, principalmente quando a taxa de glicose fôr baixa; mas a percentagem elevada de eosinófilos e a positividade da reação para cisticercose permitem a diferenciação; $c$ ) nas meningites a vírus verificam-se alterações do líquor aproximadamente semelhantes àquelas da meningite tuberculosa; entretantó, a taxa de glicose está sempre normal ou aumentada e, mesmo naqueles casos raros em que ela estiver discretamente diminuída, o exame de uma segunda amostra de líquor vem evidenciar tendência franca à normalização dos vários elementos, independentemente do curso clínico da moléstia, que pode ser bom ou mau; também a taxa de glicose faz o diagnóstico diferencial entre a meningite tuberculosa e abscesso encefálico, pois, nesta última, a taxa de açúcar é sempre normal ou elevada, embora as demais alterações possam ser semelhantes; $d$ ) no pós-operatório dos pacientes neurocirúrgicos há alterações do líquor, de tipo meningítico asséptico, podendo, entretanto, às vêzes, ocorrer diminuição da taxa de glicose; porém, nestes pacientes, a pleocitose inicial é sempre predominantemente neutrófila e o exame de amostras seriadas revela progressiva normalização do líquor; e) outra circunstância em que ocasionalmente podemos verificar a taxa de glicose diminuída, associada a um quadro de irritação meníngea, é a fase que se segue ao derrame sangüíneo no espaço subaracnóideo, mas, nestes casos, o diagnóstico diferencial não oferece dificuldades.

\section{RESUMO}

O conhecimento do líqüido cefalorraqueano inicial na meningite tuberculosa tem particular interêsse porque dêle depende a precocidade do diagnóstico e a decisão para o comêço do tratamento específico. 
O material selecionado para o estudo constituiu-se de 143 casos, cuja comprovação foi feita, num primeiro grupo, pelo achado do bacilo de Koch ao exame direto ou pela inoculação em cobaia e, num segundo grupo, pelas alterações sugestivas do líquor, associadas ao quadro clínico e foco contagiante. Foi feito estudo detalhado dos diversos elementos do exame do líqüido cefalorraquidiano, isto é, pressão, índice de Ayala, aspecto, côr, presença de retículo fibrinoso, citologia global e específica, taxa de proteínas totais, reações das globulinas, taxas de cloretos e de glicose, reações do benjoim coloidal e de Takata-Ara, reação de Wassermann, reação de floculação de Eagle, reação de Steinfeld, reação de fixação do complemento para cisticercose e exame bacterioscópico direto.

Em face da baixa freqüência do achado do bacilo ao exame direto, o estudo destas alterações do líquor assume grande importância para o diagnóstico da meningite tuberculosa.

Verificou-se em nosso material o seguinte quadro médio, caracterizando a síndrome do líquor nessa moléstia: pressão, $37 \mathrm{~cm}$ de água, com o paciente em decúbito lateral; líquor opalescente e incolor, com retículo fibrinoso presente; células, 242 por $\mathrm{mm}^{3}$ (linfócitos $77,85 \%$; mononucleares $4 \%$; plasmócitos $2 \%$; granulócitos neutrófilos $16 \%$; granulócitos eosinófilos $0,1 \%$; granulócitos basófilos $0,05 \%$ ); proteínas totais $1,16 \mathrm{~g} / 1$; reação de Pandy +++ ; reação de Weichbrodt + ; reação de Nonne ++; reação do benjoim coloidal 00000.22222 .22200 .0 ; reação de TakataAra positiva, tipo vermelho; taxa de cloretos $6,67 \mathrm{~g} / \mathrm{l}$; taxa de glicose 0,34 $\mathrm{g} / \mathrm{l}$; reação de Wassermann negativa; bacilo de Koch presente (exame direto ou inoculação).

Foram feitas considerações em tôrno do diagnóstico diferencial com a meningite luética, cisticercose encefálica, meningite a vírus, meningite do pós-operatório neurocirúrgico e hemorragias meníngeas.

\section{SUMMARY}

The authors studied 143 cases of tuberculous meningitis, selecting the patients in two groups: the first group included those cases in which the B.K. was seen by the direct examination or by inoculation of guinea pig; the second group included cases in which suggestive changes in the spinal fluid were present in association with the clinical picture and presence of specific lesion.

The spinal fluid examination included pressure values, aspect, color, fibrin net, cell count (total and specific), total proteins, globulin reactions, chlorides and glucose values, colloidal test, Wassermann test, Eagle test, Steinfeld test, complement reaction for cysticercus and direct bacterioscopic examination. 
The examination of the spinal fluid acquires great value on the diagnosis of tuberculous meningitis due to the difficulty in identifying the B.K. by direct examination.

The authors found an average characteristic spinal fluid picture in the tuberculous meningitis: pressure, $37 \mathrm{~cm}$ of water, with the patient in lateral decubitus; opalescent in aspect, colorless, with fibrin net; 242 cells per $\mathrm{mm}^{3}$ (77.85 per cent of lymphocytes, 4 per cent of polymorphonuclear leucocytes, 2 per cent of plasma cells, 16 per cent of granulocytes neutrophyls, 0.10 per cent of eosinophyls, 0.05 per cent of basophyls); total proteins $1.16 \mathrm{gm}$. per liter; Pandy test +++ ; Weichbrodt test + ; Nonne test ++ ; benjoim colloidal test 00000.22222 .22200 .0 ; Takata-Ara test posi!ive; red type of curve; chlorides $6,67 \mathrm{gm}$. per liter; glucose $0,34 \mathrm{gm}$. per liter; Wassermann test negative; B.K. present (direct examination or inoculation).

Differential diagnosis is made with syphilitic meningitis, cerebral cysticercosis, virus meningitis, meningitis that occurs in post-operative period in neurological patients and subarachnoid hemorrhage. 